\title{
Earthquake and hurricane coupling is ascertained by ground-based laser interferometer and satellite observing techniques
}

M. N. Dubrov ${ }^{1}$, V. A. Volkov ${ }^{2}$, and S. P. Golovachev ${ }^{1}$

${ }^{1}$ Kotel'nikov Institute of Radioengineering and Electronics, Russian Academy of Sciences Fryazino, Moscow Region, Russia

${ }^{2}$ Institute of Physics of the Earth, Russian Academy of Sciences, Moscow, Russia

Received: 12 December 2013 - Accepted: 4 January 2014 - Published: 30 January 2014

Correspondence to: M. N. Dubrov (mnd139@ire216.msk.su)

Published by Copernicus Publications on behalf of the European Geosciences Union.
Earthquake and hurricane coupling

M. N. Dubrov et al.

Title Page

Abstract

Introduction

Conclusions

References

Tables

Figures

14

I

4

Back

Close

Full Screen / Esc

Printer-friendly Version

Interactive Discussion 


\section{Abstract}

The most destructive disasters such as the strongest earthquakes and the most powerful tropical cyclones can be treated as tightly coupled geophysical phenomena in their origin. Results of comparison of geophysical field variations and seismic activity of the 5 Earth have evidently shown the correlation between lithosphere-atmosphere interactive disturbances, tropical cyclonic activity in the World Ocean, and seismic processes in the solid Earth. The ground-based laser interferometer techniques being supplemented by satellite observational systems can be considered as promising methods for common earthquake and hurricane monitoring and prediction.

\section{Introduction}

Catastrophic earthquakes and powerful tropical cyclones (typhoons, hurricanes) are the strongest natural disasters, which bring the colossal human and environmental losses, remain not quite clear geophysical phenomena in their origin up to date. The wide spread anomalies in deformations (tilts and strains) of the solid Earth which are often preceding to the strongest earthquakes, and which are observed in experiments by many authors for a long time (Rikitake, 1976; Mogi, 1985), have a great analogy with barometric forerunners of such extreme atmospheric events as storms, typhoons, hurricanes etc. The similarity will increase considerably if we take into account the conventional dilatancy-diffusion earthquake model and the frequently detected cove-shape precursor varieties before the most powerful earthquakes (B. I. Volkov et al., 1999; Sobolev and Ponomarev, 2003). In particular the deformation (tilt and strain) precursors are often accompanied by the peculiar tremor precursors, which are known as a reducing of micro-seismic and acoustic noise background before earthquakes - quite similar as calm before the storm. It was required a few decades to recognize the assumption of strain-meter inventor (Benioff et al., 1959) that Earth's background free oscillations in the $\mathrm{mHz}$ range are excited continuously even on seismically quiet days, and that

\section{NHESSD}

2, 935-961, 2014

Earthquake and hurricane coupling

M. N. Dubrov et al.

Title Page

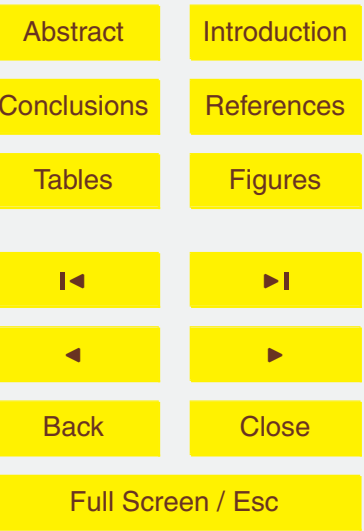

Printer-friendly Version

Interactive Discussion 
such oscillations could be aroused by atmospheric disturbances (Nishida et al., 2000). For example, the fundamental spheroidal modes $(2.0-7.5 \mathrm{mHz})$ were observed in the Earth's oscillation spectrum even in periods of the least seismic activity (Dolgikh et al., 1983; Petrova and Volkov, 1996; Kobayashi et al., 1998). The mode amplitudes are 5 sufficiently large to be attributed to small background earthquakes. The most powerful atmospheric disturbances - tropical cyclones (storms, typhoons, hurricanes) achieving the daily dissipation energy orders of $10^{18}-10^{19}$ joules (which are compared to the strongest earthquakes) - run out as the proper candidates for such stimulus of global perturbations. From the above points of view the Earth seismic activity and tropical cy-

clogenesis should be the tightly bound geophysical processes. Enouncements for this coupling have been already obtained: the interrelation of typhoons and catastrophic earthquakes was found from satellite images of cloudiness over the north-west part of Pacific Ocean (Morozova, 2006); a year seasonal correlation of cyclonic and seismic activity has been also approved basing upon the catalogues data for this region (Yaroshevich, 2010). Meanwhile the direct measurements of lithosphere and atmosphere interactions are possible only by the most accurate ground-based superconducting (Kobayashi and Nishida, 1998) and laser instruments (Takemoto et al., 2006). But according to world-wide referred papers these facilities have not been applied for investigation of specific interest outlined. Deformations and stress processes accompanying the powerful earthquakes and their coupling with tropical cyclones were not observed and studied in experiments up to now. The first approach towards the solution of this problem by means of precise laser interferometer-strain-meters combined with high sensitive pendulum instruments and comprehensive satellite observational data are presented in this paper.

\section{Earth surface deformations and atmosphere disturbances}

The long-term parallel observations of non-stationary phenomena in upper layers of the Earth's crust and in an atmosphere, which have been carried out by many au-

\section{NHESSD}

2, 935-961, 2014

Earthquake and hurricane coupling

M. N. Dubrov et al.

Title Page Introduction

Conclusions

Tables

References

Figures

14

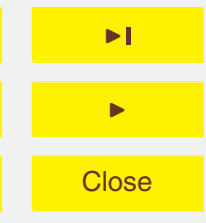

Back

Close

Full Screen / Esc

Printer-friendly Version

Interactive Discussion 
thors with help of the different geophysical instruments during the diverse years, show the existence of the determined connection between atmospheric and lithospheric processes in a wide frequency band. One could be referred to investigations of the Earth crust strains under affection of atmospheric cyclones which was made decades ago 5 (Trubitsyn et al., 1976), or e.g. to the numerical analysis of lithosphere response to atmosphere pressure variations which was performed by far later (Lyubushin, 1992; Latynina and Vasil'ev, 2001; Klügel and Wziontek, 2009). The model of interaction between the solid Earth's surface waves and atmospheric sound waves was built by Kobayashi et al. (1998) and Nishida et al. (2000), who took into account the convec10 tive motions and the heat transport in the atmosphere. This model could explain the random and stochastic disturbances which are always at any seismic or geodynamic records. But the distinguished features of many anomalous processes in these adjacent and interacting geospheres are the presence of sporadic wave-shape and other extraordinary appearances which are simultaneously recorded both in the lithosphere and in the atmosphere of the Earth eventually if such everyday meteorological interferences as winds, precipitations, and local thermo-mass-exchanges are not accounted (Dubrov et al., 1998). The origins of such kind of sporadic "signals" are not quite clear up to now.

As a rule, these anomalous events are attended by the gaining of seismic activity and 20 often - by powerful earthquakes. As an example of those lithosphere and atmosphere excitations, we would present the joint data analysis of the two synchronous operating and spatially distanced at $40 \mathrm{~km}$ ground-based instruments: seismo-gravimeter and laser strainmeter installed in Moscow region (Volkov et al., 1999a). A few month observations in 1998 within ultra long period $(3 \mathrm{~min} . .6 \mathrm{~h}$ ) band have yielded the one striking appearance of a strong synchronous gravity and strain-baric disturbance which has been followed by the essential growth of earth ground oscillations with $4-5 \mathrm{~h}$ periods together with the atmospheric pressure micro-variations in the same period range. This performance was observed 2-7 days before the very strong remote earthquake $M=8.1$ in Southern Hemisphere. That was the first our good approach in direct finding
NHESSD

2, 935-961, 2014

Earthquake and hurricane coupling

M. N. Dubrov et al.

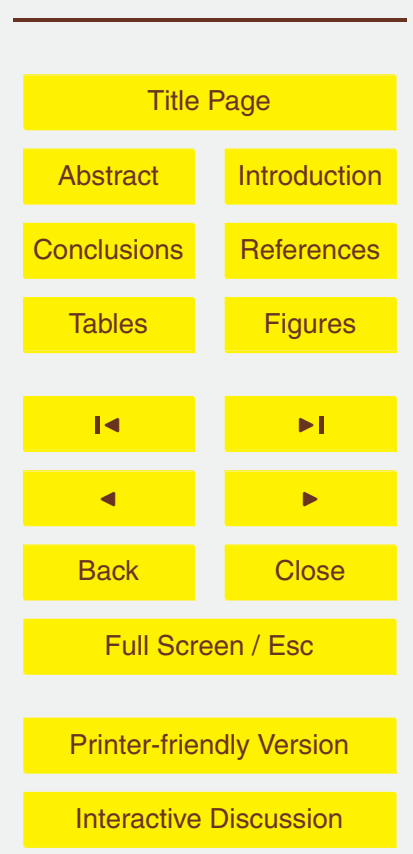

(1) 
the valuable indications of remote earthquake precursors in lithosphere-atmosphere interaction. But the problem had still remained: how we should explain so far distant $\left(\sim 10^{4} \mathrm{~km}\right)$ display of such unusual earthquake forerunner? Why these precursors were not noticed or were too small in recordings yielded from another high sensitive laser 5 instruments (Takemoto et al., 2006; Amoruso and Crescentini, 2009) installed deep underground. The comprehension has come when the activity of tropical cyclones (hurricanes, typhoons) has been taken into consideration. The maxima of their dissipation energy rates of 1018-1019 joules per day for the most powerful hurricane (typhoon) of the highest Category 5 on the Saffir-Simpson hurricane scale (SSHS) are correspon10 dent to energy orders of the strongest earthquakes with magnitude $M=8-9$. These powerful atmosphere events which are permanently performed in tropical regions of the World Ocean could disturb all the Earth (probably from the inner core up to high ionosphere) similar to strong earthquakes exciting tremors of the whole Earth in the $\mathrm{mHz}$ range. Just this link was lacking in Kobayashi (1998) and Nishida (2000) models 15 for adequate explaining the continuous forcing of background Earth's free oscillations.

\section{Laser interferometers and graviinertial tools in earthquake monitoring}

The quantitative correlation analysis of geophysical occurrences in lithosphere and in adjacent geospheres has become possible after the high precision and low noise superconducting gravimeters and long-path laser interferometers (laser strainmeters) 20 priate tools for the wideband observations of the Earth's surface motions up to now (Takemoto et al., 2006; Amoruso and Crescentini, 2009). In distinction from high resolution gravimeters (and seismo-gravimeters) laser strainmeters are more sensitive to share earth deformations and consequently to origin of seismic processes as well as to possible involvement of atmosphere disturbances into co-seismic phenomena. These features are also inherent to precise pendulum tiltmeter instruments which are applied in our observations. During the last decades we have collected and summarized the

\section{NHESSD}

2, 935-961, 2014

Earthquake and hurricane coupling

M. N. Dubrov et al.

Title Page

Abstract

Introduction

Conclusions

Tables

References

Figures

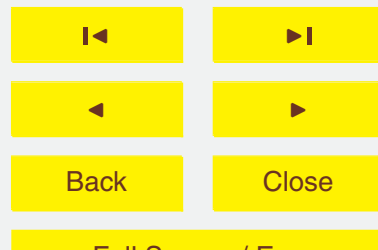

Full Screen / Esc

Printer-friendly Version

Interactive Discussion 
number of experimental data in laser and pendulum instrument geophysical studies of the anomalous deformations and seismo-acoustic phenomena foregoing to earthquakes since our first tangible results (Dubrov et al., 1992; Petrova and Volkov, 1996).

The typical examples of the remote earthquake recordings at the Moscow region 5 testing site are shown in Fig. 1. The upper trace (27 September 1974, Hokkaido, $M=7.0$ ) was obtained by $100 \mathrm{~m}$ long equal-arms laser strainmeter (Dubrov and Karmaleeva, 1976). The middle one (20 March 2008, Southern Xinjiang, $M=7.2$ ) has been recorded by $100 \mathrm{~m}$ wideband unequal-arms laser strainmeter (Dubrov et al., 2007). Durations of these two records are about of $1 \mathrm{~h}$. The earthquake origins are 10 pointed by arrows and the shear seismic waves with amplitudes of $0.5-1 \mu \mathrm{m}$ appear on the both records $20-30$ min later. The equal-arms instrument is sensitive to relative base-length variations $\mathrm{dL}$, while the unequal-arms being air-filled and non-tight interferometer records both the relative base-length $\mathrm{dL}$ variations and air pressure $\mathrm{dP}$ variations simultaneously: strain-baric atmosphere perturbations 10 min before the main shock could be seen on the middle trace of Fig. 1 ; its amplitude is less than 0.1 mbar. Long-term recordings of co-seismic processes during catastrophic Sumatra $M=9.1$ (26 December 2004) earthquake are shown on the lower trace of Fig. 1. Two tilt-baric anomalies are clearly seen on the uniform linear $20^{\prime \prime}$ instrument drift of 24 days duration. They occurred 8 days and 3 days before the main shock (pointed by arrow).

In results of our experience we have found that the dynamic disturbances of the Earth's surface and perturbations in atmosphere have a nearly wave microstructure and are often accompanied by the ascending of seismic activity. By means of spatially distributed laser instruments we could observe the traveling strain-baric anomalies (wave-shape disturbances of the atmospheric pressure and synchronous earth strain, 25 gravity and tilt variations). Their spreading velocities vary from $30-60 \mathrm{~km} \mathrm{~h}^{-1}$ if they are recorded deep into the continental zone (V. A. Volkov et al., 1999; Dubrov et al., 2007) and up to $250 \mathrm{~km} \mathrm{~h}^{-1}$ - nearby the coastal region (Dolgikh et al., 2006). The observed anomalous lithosphere activity (which the earthquake precursors should be attributed to) looks like as interference of the Earth's surface with atmosphere, hydrosphere in-

\section{NHESSD}

2, 935-961, 2014

\section{Earthquake and hurricane coupling}

M. N. Dubrov et al.

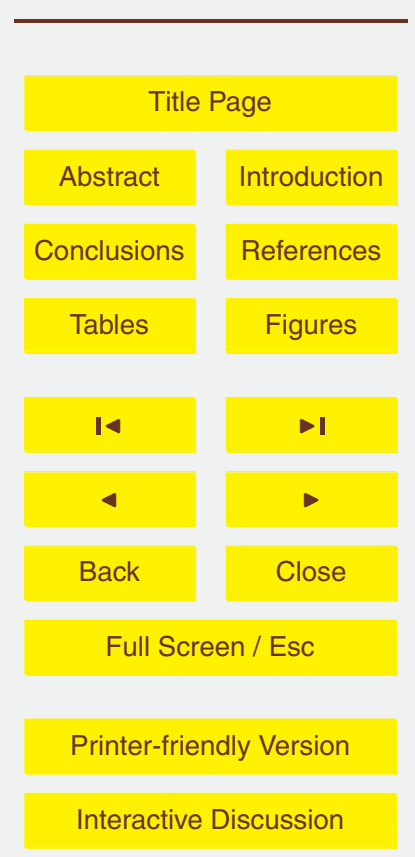

(i) 
cluding an underground water level (Dubrov et al., 2007), and upper geosphere layers (Dubrov and Smirnov, 2013). From this point of view the coupling of lithosphere activity and powerful processes in the World Ocean is justified and should be taking into account.

\section{Earthquakes and tropical cyclogenesis}

If we cast a glance at two well known and referred elsewhere maps: (1) the global hurricanes track records, and (2) the global distribution of earthquake centers, we should see two important things. There are few particular regions in the World Ocean basin which show the spatial correlation between earthquake and hurricane occurrences. 10 These regions are: North Atlantics (low correlation), South West Pacific (moderate correlation), and North West Pacific (high correlation). Meanwhile correlation is not observed in other specific regions, e.g. in South East Pacific and South Atlantics. A lot of ideas would be suggested for explanation of this circumstance. There are many publications and studies dedicated to earthquakes and hurricanes interaction. But any 15 approach to this problem should be grounded on the detail studies including the instrumental investigations of conditions and situations concerned with such insufficiently explored phenomenon. Our feasible attempts to elucidate this subject using original experimental data are presented below.

The correlation between the seismic activity of the Earth and the tropical cyclogen20 esis in the World Ocean we demonstrate by few examples of parallel recordings obtained by long-path laser interferometers, seismo-gravimeters, and tiltmeters during the powerful earthquakes in 1998-2004. The comparison with global and regional cyclogenesis has become possible owing to issuing the Catalog of Tropical Cyclones and Tropical Disturbances of the World Ocean for 1983-2005 (Pokrovskaya and Sharkov, (http://weather.unisys.com/) (http://en.wikipedia.org/wiki/Portal:Tropical_cyclones) re-

NHESSD

2, 935-961, 2014

Earthquake and hurricane coupling

M. N. Dubrov et al.

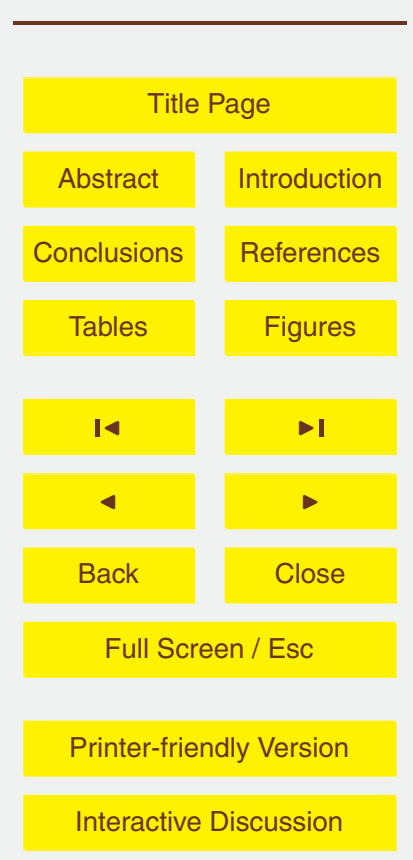


cent years. Let us consider the regions of the World Ocean mentioned above each taken separately.

\subsection{North Atlantic Ocean}

This active region of the World Ocean is the nearest basin to the place of our instru5 ment installations where the studied phenomena developments are the most legible. Exemplary comparison of recorded strain-baric variations and tropical cyclone activity in the North Atlantics are presented on Fig. 2. We have performed the analysis of our experimental data obtained by $100 \mathrm{~m}$ laser interferometer located at the Fryazino underground testing site (Moscow region) and two tropical disturbances which have been detected in the end of September 2001. The tropical disturbance FELIX ATL 0106 (Pokrovskaya et al., 2006, pp. 500-501) mounted the typhoon (hurricane) stage on 13-17 September 2001 with maximum wind velocity of $51 \mathrm{~m} \mathrm{~s}^{-1}$ and dissipated on 23 September 2001 (23 September 2001, see Fig. 2). But this day the second disturbance HUMBERTO ATL 0108 mounted to the typhoon (hurricane) stage - wind velocity more 15 than $33 \mathrm{~ms}^{-1}$ (left column of the diagram in Fig. 2) and epicenter drift velocity (middle column of the diagram) established its minimum value about 10 miles $\mathrm{h}^{-1}$ this day. During 22-24 September 2001 the laser interferometer recorded anomalous waveform strain-baric variations which have been rarely observed by this instrument (see 3 traces to the right in Fig. 2).

20 It is remarkable that the most intensive wave-shape strain and atmosphere pressure variations have been recorded just the day 23 September 2001 and in the time for $2 \mathrm{~h}$ preceding the origin of an earthquake which was the nearest seismic event from the site of our observations during the considered 3 day interval. This earthquake occurred in Greece $\left(37.73^{\circ} \mathrm{N}, 21.04^{\circ} \mathrm{E}\right.$, magnitude $\left.M=4.7\right)$, its origin time 21:16 23 September 2001 has been pointed by arrow on Fig. 2. The others from about three dozen earthquakes $M=4.0-5.8$ for this period (Geophysical Survey of Russian Academy of Sciences, 2003) were less intensive $(M<4.7)$ or were happened too far from our testing site, e.g. in Colombia $M=5.8$, Alaska $M=5.3$, New Zealand $M=5.0$ etc.

NHESSD

2, 935-961, 2014

Earthquake and hurricane coupling

M. N. Dubrov et al.

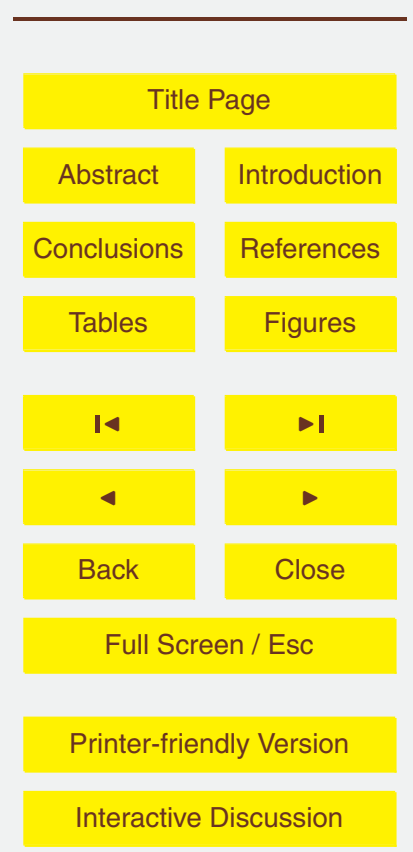


The recorded temporal strain-baric variations occupied the period range 5-40 min. The spatial scale of the observed phenomenon covered the Anatolian and Balkan regions that have been approved by the simultaneously recorded ionosphere disturbances that refined from the satellite data processing for this period (Dubrov and 5 Smirnov, 2013).

\subsection{South Pacific and Indian Oceans}

To illustrate the results of measurements concerning this part of the Southern Hemisphere let us consider already mentioned above the striking detection of anomalous lithosphere-atmosphere activity that was observed in Moscow region on March 1998.

10 The maximum intensity of those gravity and strain-baric perturbations was recorded about $50 \mathrm{~h}$ before the strongest earthquake at the Earth for the whole 1997-1998 seasons. Because of very large distance to the earthquake region $\left(\sim 10^{4} \mathrm{~km}\right)$ the connection of recorded data to powerful seismic event $M=8.1$ (NEIC, 1998) for the first opinion seemed to be hardly probable. But thorough analysis of the presented data brings the new sense of occurring geophysical phenomena.

The results of experimental detection of lithosphere-atmosphere processes from 13 March 1998 to 31 March 1998 are shown on the left diagram in Fig. 3. The recordings of atmosphere pressure variations $(\mathrm{dP})$, gravity $(\mathrm{dG})$, and earth surface strains $(\mathrm{dL})$ are presented here. Measurements have been fulfilled at two sites which were 20 spatially distanced at $40 \mathrm{~km}$ one from another within the bounds of Moscow region. These data have been compared with two rows of the most powerful natural performances at the Earth which were going on March 1998:

1. Three severe tropical cyclones in SW region of Pacific: 16-27 March 1998, Yaly; 18-31 March 1998, Nathan; 26 March-06 April 1998 Zuman; and severe storm Sharkov, 2006);

NHESSD

2, 935-961, 2014

Earthquake and hurricane coupling

M. N. Dubrov et al.

Title Page

Abstract

Introduction

Conclusions

Tables

References

Figures

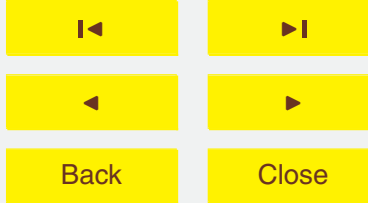

Full Screen / Esc

Printer-friendly Version

Interactive Discussion 
2. Three of the strongest earthquakes on this time interval: 25 March 1998, Balleny Islands, $M=8.1$; 29 March 1998, Tonga Islands, $M=7.2$; and 1 April 1998, Southern Sumatra, $M=7.0$ (NEIC, 1998).

All these powerful cyclonic (1) and seismic (2) events are presented on the right dia5 lines and the strongest seismic events are depicted by vertical arrows. Severe tropical storm Elsie in the Indian Ocean has been classified as category 2 tropical cyclone (SSHS) with maximum winds of $V_{\mathrm{m}}=90-100$ miles $^{-1}\left(42-47 \mathrm{~m} \mathrm{~s}^{-1}\right)$. Two SW Pacific cyclones Yaly and Zuman had category 2 and 3 tropical cyclone (SSHS) with wind 10 speeds $V_{\mathrm{m}}$ in peak intensity above 80 miles $^{-1}\left(36 \mathrm{~m} \mathrm{~s}^{-1}\right)$ and $90 \mathrm{miles} \mathrm{h}^{-1}\left(42 \mathrm{~m} \mathrm{~s}^{-1}\right)$ respectively. The cyclonic condition was notable less disturbed 16 days before the Elsie's origin: the nearest such or higher power tropical cyclones and storms were observed as early as from January up to the first half of February. The low disturbed condition remained so after Zuman dissipation: tropical cyclones of category 2 SSHS or higher were not observed after 6 April within 1997-98 SW Indian Ocean, Australian region, and South Pacific cyclone seasons. The Earth's seismic condition conforms to this course of events. It remained relatively quiet on February and April 1998. The nearest strong $(M>7.0)$ earthquakes occurred before: as early as in 30 January (Northern Chile, $M=7.1$ ) and after: on 3 May 1998 (Southeast of Taiwan, $M=7.5$ ).

20 Let's consider the results of recordings of atmosphere pressure variations, the Earth's surface strains, and gravity variations, which are presented on the left diagram in Fig. 3. The strain (dL) and gravity (dG) data show the contrast cove-shape anomaly on the near uniform drift and tidal signals. This anomaly has duration about 6 days by 18-23 March and agrees with the significant atmospheric pressure (dP) variations. It been started just after tropical cyclone Elsie dissipation and it is the moment when tropical cyclone Yali is reaching hurricane stage: wind velocity has forced more than $33 \mathrm{~ms}^{-1}$ (see triangular mark in Fig. 3).

NHESSD

2, 935-961, 2014

Earthquake and hurricane coupling

M. N. Dubrov et al.

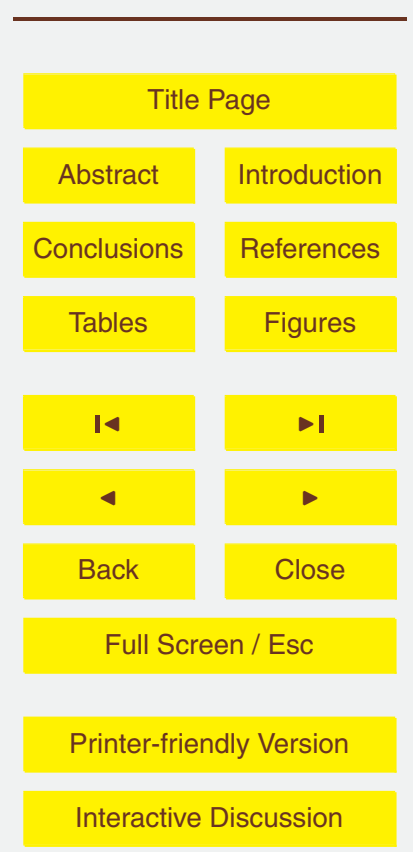

(1) 
The development of growth of earth ground oscillations with ultra-long 4-5h period range mentioned above is shown in Fig. 4. Near the smooth diurnal ground strains (dL) on 21-22 March and 24-25 March are sharply disturbed by considerable variations of $\mathrm{dL}=0.3-0.5$ micron with $3.9 \mathrm{~h}$ and $5.5 \mathrm{~h}$ oscillation periods on $22-23$ March. It is 5 important that similar oscillating disturbances have been observed in the atmospheric pressure records with amplitudes up to $\mathrm{dP}=0.8-0.9 \mathrm{mbar}$ with the same characteristic phases. These processes proceeded more than $50 \mathrm{~h}$ and were not recorded ever more during for all 6 month cycle of those observations in Moscow region in 1998.

\subsection{North Pacific Ocean}

10 The basin of North Pacific in particular its West side is characterized as the most active cyclone region of the World Ocean. Similarly the same feature should be given to the West Pacific as the most active seismic region of the Earth. Let's consider this situation in more detail on example of hurricanes and earthquakes which occurred in 2003.

Eighty eight tropical cyclones were recorded in the World Ocean during period from 15 January to December 2003 (Pokrovskaya et al., 2006, pp. 567-573). Above the half of them has mounted the typhoon (hurricane) stages when their wind velocities exceeded $33 \mathrm{~ms}^{-1}$. The most powerful hurricane (super-typhoon MAEMI NWP0315) with the maximum wind velocity of $78 \mathrm{~ms}^{-1}\left(170\right.$ miles $\left.^{-1}\right)$ in the upper stage of evolution walked at the North West Pacific in the first half of September 2003. It has been classi-

20 fied as the highest Category 5 SSHS. If we take the seismic data into consideration we find them to be excellently correlated with the processes of tropical cyclone developments: the strongest earthquake of the year 2003 was happened just in September and just in the North West Pacific basin, namely: Hokkaido region, date 25 September 2003 (magnitude $M=8.3$ ). The details of these and other powerful events are presented in 25 Table 1 and Table 2.

The hurricanes and typhoons which occurred in North West (NWP) and North East Pacific (NEP) two weeks before and two weeks after the Hokkaido $M=8.3$ earthquake are included in Table 1. The tropical cyclones of Category 2 SSHS and higher have

\section{NHESSD}

2, 935-961, 2014

Earthquake and hurricane coupling

M. N. Dubrov et al.

Title Page

Abstract

Introduction

Conclusions

Tables

References

Figures

14

$\rightarrow$ I

4

Back

Close

Full Screen / Esc

Printer-friendly Version

Interactive Discussion 
been concern to. The earthquakes with magnitude $M>6.0$ which occurred on the Earth during the same period 8 September-8 October 2003 are included in the Table 2 with numbers and parameters according to Operative Seismological Catalogue from Obninsk Observatory (Geophysical Survey of Russian Academy of Sciences, 2003).

$5 \quad$ Earthquake temporal distribution has been compared with NWP typhoons evolutions and the results are shown in Fig. 5. Tropical cyclone developments are presented by velocity variations of sustained winds for the NWP typhoons while the origin times and durations of the NEP hurricane are shown by horizontal lines. Temporal distribution of earthquakes with $M>6.0$ is shown as time diagram of vertical arrows (Fig. 5).

The maximum of seismic activity (earthquake 3646 on 25 September 2003) conforms to period of NWP typhoons power descent but NEP hurricanes activity growth. Three strongest earthquakes with $M=7.2-8.3$ occurred in period from 24 September 2003 to 28 September 2003 when damping of both NWP and NEP tropical cyclone activity was observed.

15 Earthquake precursor in form of seismic-acoustic calmness was recorded by laser strainmeter at Fryazino testing site in this period (Fig. 5b and c). The phenomenon of envelope modification of coherent short-period microseisms at industrial frequencies $F_{\mathrm{i}}=50 / i \mathrm{~Hz}, i=1,2,3, \ldots$, which amplitude variations are synchronized to the strongest remote earthquakes with probability over 0.9 was found and approved decades ago (Dubrov et al., 1992) The precursor has become apparent as fading the amplitudes of spectral components at frequencies $F_{18}$ and $F_{26}$ in $1-3 \mathrm{~Hz}$ band during about $8 \mathrm{~h}$.

The most intensive components $1.94 \mathrm{~Hz}$ and $2.79 \mathrm{~Hz}$ in this band are about of 64 relative units in amplitude (see column of brightness scale to the right of each timefrequency diagrams on Fig. $5 b$ and c) before precursor development. On 26 September their amplitudes diminished more than 7 times and during the "microseismic calm" they become almost invisible at random background level with amplitudes of 9-10 units (Fig. 5c). This level defines the resolution limit of the applied strainmeter system $\mathrm{dL} / L \approx$ $10^{-12}$.

\section{NHESSD}

2, 935-961, 2014

Earthquake and hurricane coupling

M. N. Dubrov et al.

Title Page

Abstract

Introduction

Conclusions

Tables

References

Figures

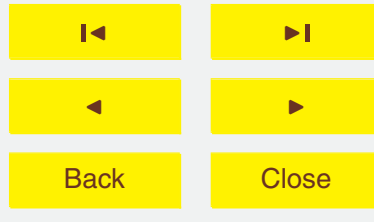

Full Screen / Esc

Printer-friendly Version

Interactive Discussion 


\section{Discussion of the results}

The results presented in previous sections have been obtained by means of precise laser strainmeters combined with high sensitive pendulum instruments and satellite observational data. These results show the existence of certain relation between seismic 5 processes and tropical cyclogenesis. However this relationship is not utterly definite: there is a good temporal coupling between earthquakes and hurricanes (typhoons), while their spatial correlation is spread only on the particular World Ocean regions.

Important deductions which can elucidate the physical model of hurricanes and earthquakes interaction are inferred from Sects. 4.1-4.3. The common peculiarity is inherent to coupling the considered seismic processes and tropical cyclones in North Atlantics, in South Pacific and Indian Ocean, and in North Pacific. Earthquake 23 September 2001 in Europe (Greece, $M=4.7$ ) occur when hurricane FELIX ATL 0106 has been dissipated and tropical disturbance HUMBERTO ATL 0108 mounted to the typhoon (hurricane) stage (Fig. 2). The similar processes are observed for sequence of South Indian Ocean (SIO) and South West Pacific (SWP) cyclones: severe SIO storm ELSIE is followed by three SWP typhoons YALY, NATHAN and ZUMAN (Fig. 3) when three earthquakes including the strongest one of 1997-1998 seasons have been happened. At last the North Pacific performances: during the NWP typhoons MAEMI, CHOI-WAN, and KOPPU dissipations the NEP hurricanes MARTY and NORA are developed (Fig. 3), meanwhile the formed gap of cyclonic activity has been just filled by the strongest earthquakes. These West-East swings of the Earth's crust being forced by so strong vortex atmosphere perturbations could be the cause of the crust faults triggering and earthquake occurring moments provoking.

Certain features of spatial and temporal correlation between earthquakes and trop25 ical cyclones are show in the Fig. 6, where the tracks of three typhoons NWP0315NWP0317 are presented.

The next distinctions of typhoon behaviours should be noted. At the initial stage of evolution their traces walk in NW direction throw the passage between Marianas and
NHESSD

2, 935-961, 2014

Earthquake and hurricane coupling

M. N. Dubrov et al.

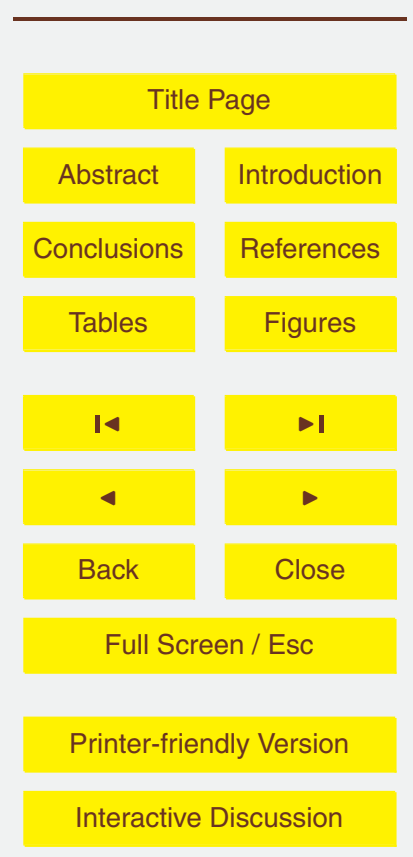


Philippine Islands. The advance of this line shows the way to the centers of future earthquakes in Central Russia (Altai). While turning at right angle to NE the typhoons walk towards the Japan and pass near the main centers of the strongest earthquake in consideration.

5 The turn point of trajectory of the third typhoon KOPPU NWP0317 is so puzzling. In this point the arising hurricane being in tropical disturbance stage (sustained winds less than $15 \mathrm{~ms}^{-1}$ ) begins to make the loops (bottom in Fig. 7). It is the time when the main catastrophic shock with magnitude $M=8.3$ was happened at Hokkaido region (it is indicated by arrow in Fig. 7). The wind velocity of tropical disturbance even 10 slightly diminished from $15 \mathrm{~m} \mathrm{~s}^{-1}$ to $13 \mathrm{~m} \mathrm{~s}^{-1}$ in succeeding period 26 September 2003 (Fig. 5a) and it was particularly the time when the microseismic calm before the next underground storm has been recorded (Fig. 5c).

Strain-baric disturbances which were observed by $100 \mathrm{~m}$ laser instrument in Moscow region this day (see top of Fig. 7) besides the shear seismic waves about of $1 \mathrm{~h}$ dura15 tiol tons contain intense long-period variations in 20-40 min range. These disturbances being in earth free oscillation frequency band $(0.4-0.8 \mathrm{mHz})$ are excited by the earthquake and they are propagated as well as in the solid Earth and in upper atmosphere and ionosphere up to $400 \mathrm{~km}$ height (Dubrov and Smirnov, 2013).

The multiform interactions of lithosphere and atmosphere disturbances in ultra long period range $(3 \mathrm{~min} . .6 \mathrm{~h}$ ) have been first investigated and analyzed in detail by the synchronous operating and spatial distributed seismo-gravimeters (Petrova and Volkov, 1996), tiltmeters, and laser strainmeters (Dubrov et al., 2000). Measurements fulfilled during the periods of low seismic activity when the disturbances have been observed before strong earthquakes are of great value. These are especial examples of recordings which have been presented in the previous sections. The found pre-seismic strainbaric, tilt-baric, and gravity-baric variations have oscillation periods from a few minutes (Fig. 1 and 2) up to $10^{3}-10^{4}$ min (Figs. 1, 3, and 4). All of them precede the earthquakes which have occurred at distances $10^{3}-10^{4} \mathrm{~km}$ from the point of registration. The origin of these pre-seismic oscillations has good explanation through mechanisms

\section{NHESSD}

2, 935-961, 2014

\section{Earthquake and hurricane coupling}

M. N. Dubrov et al.

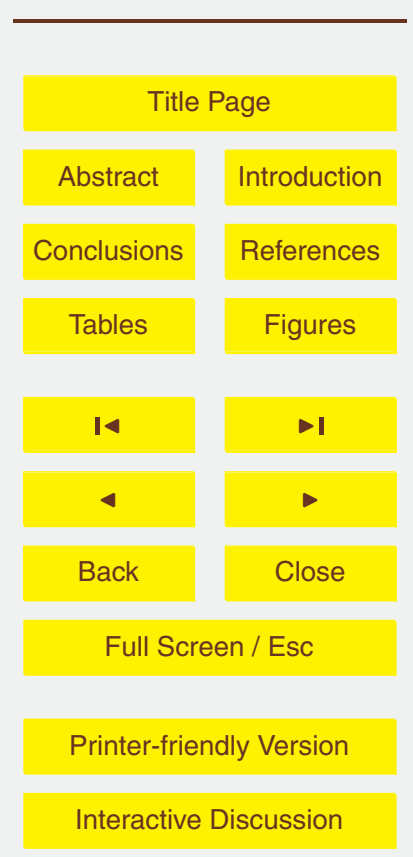


of atmosphere and lithosphere excitations by such powerful vortex disturbances as hurricanes and typhoons. It is important that periodic disturbances are accompanied by intense loading on the lithosphere due to significant pressure depressions (up to 100-200 mbar) in hurricane or typhoon active zones. The strain-baric coefficient was 5 found to be $2 \times 10^{-8}-2 \times 10^{-9} \mathrm{mbar}^{-1}$ at the depths $2-15 \mathrm{~m}$ under earth surface (Dubrov et al., 1998). These yield significant enough values of quasi-static straight loading on the ocean bottom. The mentioned periodic vortex disturbances together with quasistatic crust deformations may achieve that level in the vicinity of earthquake preparation zone when a triggering mechanism of seismic process can be started up.

The "bursts" of periodic oscillations and their synchronization before three strong earthquakes recently reported (Sobolev, 2011) could be referred to these mechanisms in full measure.

The appearing of oscillations 9 day before Hokkaido $M=8.3$ earthquake 25 September 2003 (Sobolev, 2011) agrees with our consideration in Sect. 4.3 (see Fig. 5) and 15 is explained by 3 typhoons disturbing effects. Similarly the most intense tropical cyclone BENTO Category 5 SSHS in autumn 2004 of South-West Indian Ocean cyclone season (Volkov and Dubrov, 2013) as well as the abundant 2004 series of super typhoons in Pacific Ocean should be taken into consideration to describe pre-seismic disturbances before the catastrophic Sumatra $M=9.1$ earthquake 26 December 2004 (Sobolev, 2011). If we began to investigate the track of SIO cyclone BENTO (2004) we should discover that it succeeded the strange spatial and temporal behaviors of NWP0315-NWP0317 typhoons and NEP0312 hurricane LINDA before the strong Japanese and Altai earthquakes in September 2003 (Table 1 and Fig. 6).

\section{Conclusions}

25 As a result of comparison of geophysical field variations and seismic activity of the Earth we have found the evident correlation between lithosphere-atmosphere interactive disturbances, tropical cyclone activity in the World Ocean, and seismic processes
NHESSD

2, 935-961, 2014

Earthquake and hurricane coupling

M. N. Dubrov et al.

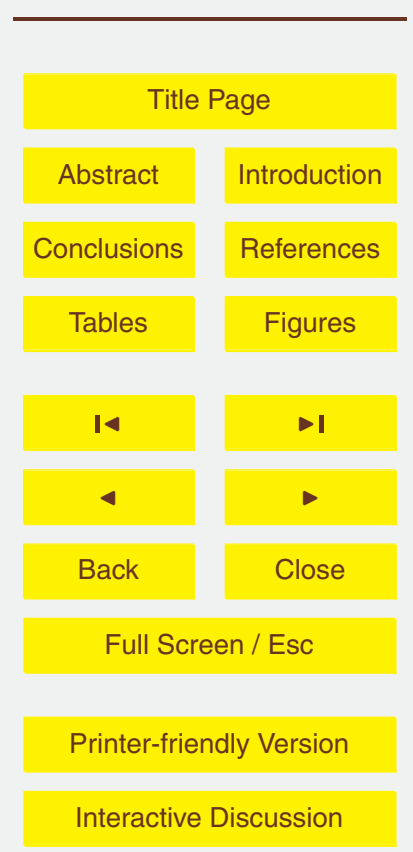


in the solid Earth. The found correlation can be interpreted as appearing or increase in amplitude the wide-band oscillations disturbed by typhoons and hurricanes which together with quasi-static pressure loading on the ocean bottom provoke powerful earthquakes through the triggering effect. The spatial and temporal tracks of tropical dis5 turbances are coupled with place and time of occurring earthquake. Investigation of the observed phenomena and deployment the detailed interaction mechanisms of the atmosphere, lithosphere, and other adjacent geospheres would give a chance to find the regularity and origins of such natural disasters as earthquakes and hurricanes.

\section{References}

Amoruso, A. and Crescentini, L.: The geodetic laser interferometers at Gran Sasso, Italy: recent modifications and correction for local effects J. Geodyn., 48, 120-125, 2009.

Benioff, H., Harrison, J. C., LaCoste, L., Munk, W. H., and Slichter, L. B.: Searching for the Earth's free oscillations, J. Geophys. Res., 64, 1334-1337, 1959.

Dolgikh, G. I., Kopvillem, U. H., and Pavlov, A. N.: Recording by optical deformometer the interaction of tropical cyclones with ocean by means of seismic channel, Tropical meteorology, Leningrad, Gidrometeoizdat, Proceedings of International Symposium, 231-235, 1982 (in Russian).

Dolgikh, G. I., Kopvillem, U. H., and Pavlov, A. N.: Observation of periods of free oscillations of the Earth by laser strainmeter, Izv. AN SSSR, Fiz. Zemli, N2, 15-20, 1983 (in Russian).

20 Dolgikh, G. I., Dubrov, M. N., Dolgikh, S. G., Kovalev, S. N., Ovcharenko, V. V., Savvin, E. A., Chupin, V. A., Shvets, V. A., and Yakovenko, S. V.: Application of laser strainmeters to the study of earthquake physics, Acta Geophys., 54, 187-197, 2006.

Dubrov, M. N. and Alyoshin, V. A.: Laser strainmeters: new developments and earthquake prediction applications, Tectonophysics, 202, 209-213, 1992.

Dubrov, M. N. and Karmaleeva, R. M.: Analysis of equal-arm laser extensometer operation and its comparison with rod extensometer, Izvestiya AN SSSR, Fizika Zemli, N7, 81-89, 1976.

Dubrov, M. N. and Smirnov, V. M.: Interdependent perturbations of the Earth's surface, atmosphere, and ionosphere, Geomagn. Aeronomy+, 53, 49-59, 2013.

\section{NHESSD}

2, 935-961, 2014

Earthquake and hurricane coupling

M. N. Dubrov et al.

Title Page

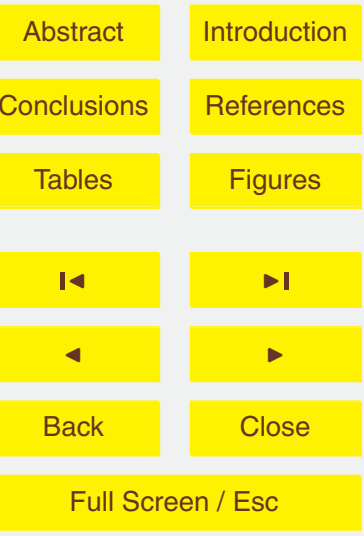

Printer-friendly Version

Interactive Discussion 
Dubrov, M. N., Latynina, L. A., Matveev, R. F., and Ponomarev, A. V.: Observation of ultralong-period earth surface strain oscillations attached to the small variations of atmospheric pressure, Izvestiya, Phys. Sol. Earth, 34, 983-990, 1998.

Dubrov, M. N., Matveev, R. F., Volkov, V. A., Latynina, L. A., and Ponomarev, A. V.: Strain, tilt, and gravity monitoring of long period and seismogravity oscillations, Proceeding of the Ninth International Symposium on Recent Crustal Movements CRCM'98, 14-19 November 1998, Cairo, Egypt, NRIAG, 1, 167-178, 2000.

Dubrov, M. N., Kazantseva, O. S., Manukin, A. B., and Ponyatovskaya, V. I.: The study of synchronously measured variations in the Earth's surface strain and groundwater level, Izvestiya,

10 Phys. Sol. Earth, 43, 404-411, 2007.

Geophysical Survey of Russian Academy of Sciences: Operative Seismological Catalogue, Central Experimental-Methodical Expedition (Obninsk), (1-30 September 2001; 130 September and 1-10 October 2003), 2003.

Klügel, T. and Wziontek, H.: Correcting gravimeters and tiltmeters for atmospheric mass attrac15 tion using operational weather models, J. Geodyn., 48, 204-210, 2009.

Kobayashi, N. and Nishida, K.: Continuous excitation of planetary free oscillations by atmospheric disturbances, Nature, 395, 357-360, 1998.

Latynina, L. A. and Vasil'ev, I. M.: Crustal Deformations Induced by Atmospheric Pressure, Izvestiya, Phys. Sol. Earth, 37, 392-401, 2001.

20 Lyubushin Jr., A. A., Osika, V. I., Pchelintsev, V. A., and Petuhova, L. S.: Analysis of response of Earth crust strains to atmosphere pressure variations, Izvestiya, Fizika Zemli, N2, 81-89, 1992.

Mogi, K.: Earthquake Prediction: Kiyoo Mogi of the Earthquake Research Institute, Academic Press, Tokyo/New York/Orlando, 355 pp., 1985.

25 Morozova, L. I.: Typhoons and seismicity, Doklady Academy, 410, 1132-1135, 2006.

NEIC: National Earthquake Information Center, US Geological Survey (USGS), Earthquake Data Base, available at: www.usgs.gov, 1998.

Nishida, K., Kobayashi, N., and Fukao, Y.: Resonant oscillations between the solid earthand the atmosphere, Science, 287, 2244-2246, 2000.

30 Petrova, L. and Volkov, V.: Dynamic features of seismo-gravitational oscillations of the Earth, Doklady Academy, 41, 683-686, 1996.

\section{NHESSD}

2, 935-961, 2014

\section{Earthquake and hurricane coupling}

M. N. Dubrov et al.

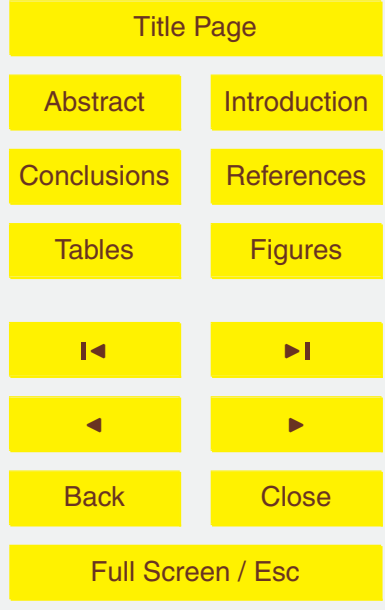

Printer-friendly Version

Interactive Discussion 
Pokrovskaya, I. V. and Sharkov, E. A.: Catalog of Tropical Cyclones and Tropical Disturbances of the World Ocean: Chronology and Evolution, Version 2.1 (1983-2005), Moscow, Poligraph Servis, 728 pp., 2006.

Rikitake, T.: Earthquake Prediction, Elsevier Scientific Pub. Co., Amsterdam, New York, 357 5 pp., 1976.

Sobolev, G. A.: Seismicity dynamics and earthquake predictability, Nat. Hazards Earth Syst. Sci., 11, 445-458, doi:10.5194/nhess-11-445-2011, 2011.

Sobolev, G. A. and Ponomarev, A. V.: Earthquake Physics and Precutsors, Nauka, Moscow, 270 pp., 2003 (in Russian).

10 Takemoto, S., Momose, H., Araya, A., Morii, W., Akamatsu, J., Ohashi, M., Takamori, A., Miyoki, S., Uchiyama, T., Tatsumi, D., Higashi, T., Telada, S., and Fukuda, Y.: A $100 \mathrm{~m}$ laser strainmeter system in the Kamioka Mine, Japan, for precise observations of tidal strains, J. Geodyn., 41, 23-29, 2006.

Trubitsyn, A. P. and Makalkin, A. B.: Deformations of Earth crust under affection of atmospheric 15 cyclones, Izvestiya AN SSSR, Fizika Zemli, N5, p. 94, 1976.

Volkov, V. A. and Dubrov, M. N.: Geodynamical observations using spatially distributed gravimeters, tilt-meters, and laser strain-meters, 17th International Symposium on Earth Tides "Understand the Earth", Warsaw, Poland, 15-19 April 2013, S-2.1, 2013.

Volkov, V. A., Dubrov, M. N., and Matveev, R. F.: The lithosphere and atmosphere interaction activity and its possible connection with coseismic process, IUGG'99 (XXII General Assembly of the International Union of Geodesy and Geophysics), Birmingham, 18-30 July 1999, Abstracts (week A and B), 171, available at: www.iugg.org/assemblies/1999birmingham/ 1999abstracts.pdf, 1999.

Volkov, B. I., Dobrovol'sky I. P., Zubkov, S. I., and Sekerzh-Zenkovich, S. Y.: Temporal shapes 25 of earthquake precursors, Izvestiya, Fizika Zemli, N4, 81-84, 1999.

Yaroshevich, M. I.: Doklady Academy, 431, 403-407, 2010.

\section{NHESSD}

2, 935-961, 2014

\section{Earthquake and hurricane coupling}

M. N. Dubrov et al.

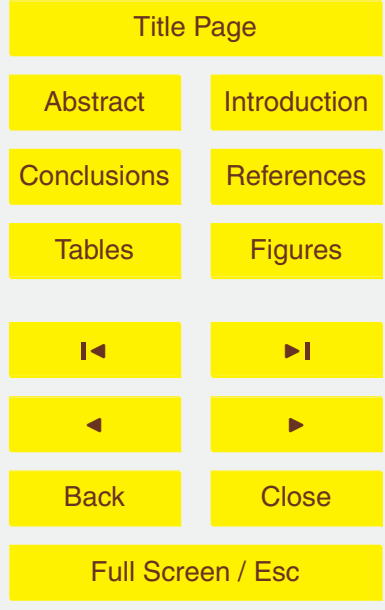

Printer-friendly Version

Interactive Discussion 
Table 1. North-West Pacific Ocean typhoons and North-East Pacific Ocean hurricanes from 7 September 2003 to 8 October 2003.

\begin{tabular}{llll}
\hline Number & \multicolumn{1}{c}{ Cyclone name } & Dates & Wind $\mathrm{m} \mathrm{s}^{-1}$ \\
\hline \multicolumn{2}{l}{ North West Pacific Ocean (NWP) } \\
\hline NWP0315 & MAEMI & 03 Sep-13 Sep & 78 \\
NWP0316 & CHOI-WAN & 17 Sep-23 Sep & 49 \\
NWP0317 & KOPPU & 22 Sep-30 Sep & 41 \\
\hline North East & Pacific Ocean (NEP) & \\
\hline NEP0312 & LINDA & 12 Sep-22 Sep (26) & 33 \\
NEP0313 & MARTY & 18 Sep-24 Sep & 44 \\
NEP0315 & NORA & 29 Sep-9 Oct & 46 \\
\hline
\end{tabular}

NHESSD

2, 935-961, 2014

Earthquake and hurricane coupling

M. N. Dubrov et al.

Title Page

Abstract

Introduction

Conclusions

Tables

References

Figures

14

4

Back

Close

Full Screen / Esc

Printer-friendly Version

Interactive Discussion 


\section{NHESSD}

2, 935-961, 2014

Table 2. Earthquakes with magnitude $M>6.0$ from 7 September 2003 to 8 October 2003.

\begin{tabular}{llll}
\hline $\mathrm{Nm}$ & Region & Date, time & $M$ \\
\hline 3422 & Loyalty Islands & 7 Sep 13:19:22 & 6.2 \\
3551 & Chile-Bolivia & 17 Sep 21:34:52 & 6.2 \\
3591 & Myanmar & 21 Sep 18:16:16 & 6.8 \\
3600 & Dominican Republic & 22 Sep 04:45:37 & 6.6 \\
3646 & Hokkaido & 25 Sep 19:50:08 & 8.3 \\
3658 & Hokkaido & 25 Sep 21:08:00 & 7.2 \\
3701 & Hokkaido & 26 Sep 20:38:22 & 6.1 \\
3722 & Central Russia & 27 Sep 11:33:26 & 7.3 \\
3763 & Central Russia & 27 Sep 18:52:47 & 6.7 \\
3844 & Hokkaido & 29 Sep 02:36:54 & 6.8 \\
3909 & Kermadec Islands & 30 Sep 14:08:41 & 6.4 \\
3927 & Central Russia & 1 Oct 01:03:25 & 6.9 \\
4109 & Samoa & 7 Oct 04:55:28 & 6.2 \\
4139 & Hokkaido & 8 Oct 09:06:57 & 6.8 \\
\hline
\end{tabular}

Earthquake and hurricane coupling

M. N. Dubrov et al.

Title Page

Abstract

Introduction

Conclusions

References

Tables

Figures

14

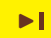

4

Back

Close

Full Screen / Esc

Printer-friendly Version

Interactive Discussion 


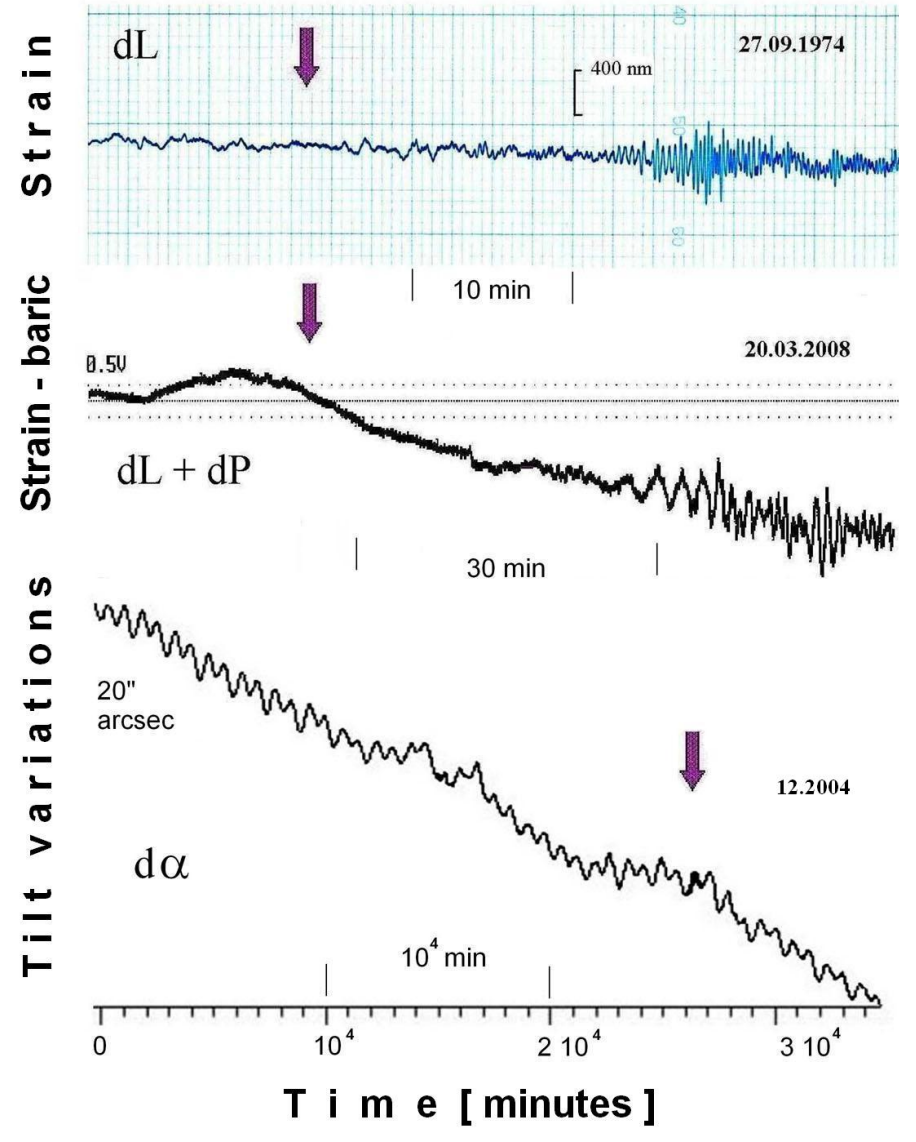

\section{NHESSD}

2, 935-961, 2014

\section{Earthquake and hurricane coupling}

M. N. Dubrov et al.

Title Page

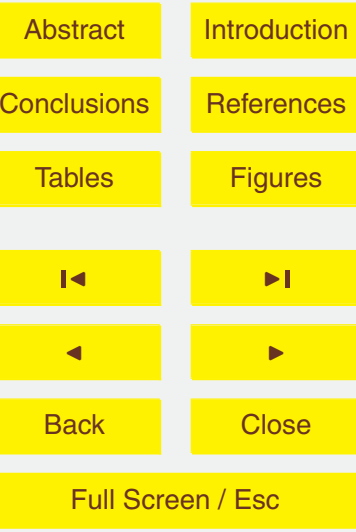

Printer-friendly Version

Interactive Discussion

Fig. 1. Strain, strain-baric and tilt variations preceding and accompanying the remote earthquakes recorded by ground-based instruments: $100 \mathrm{~m}$ laser interferometers (Dubrov and Karmaleeva, 1976; Dubrov et al., 2007) and tiltmeter (Volkov and Dubrov, 2013). 


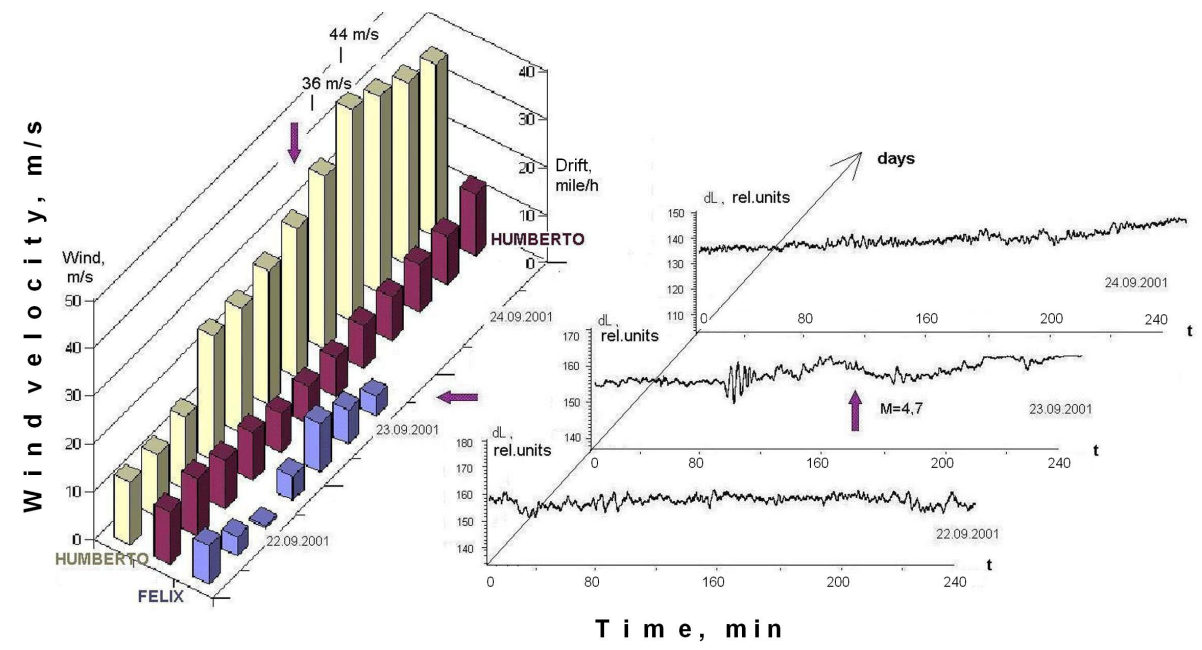

Fig. 2. Comparison of cyclone activities in North Atlantics (left) with strain-baric perturbations in Moscow region (right).

\section{NHESSD}

2, 935-961, 2014

\section{Earthquake and hurricane coupling}

\section{N. Dubrov et al.}

Title Page

\begin{tabular}{|c|c|}
\hline Abstract & Introduction \\
\hline Conclusions & References \\
\hline Tables & Figures \\
\hline I & \\
\hline 4 & $-\mathbf{~}$ \\
\hline Back & Close \\
\hline Full Screen / Esc \\
\hline
\end{tabular}

Printer-friendly Version

Interactive Discussion 

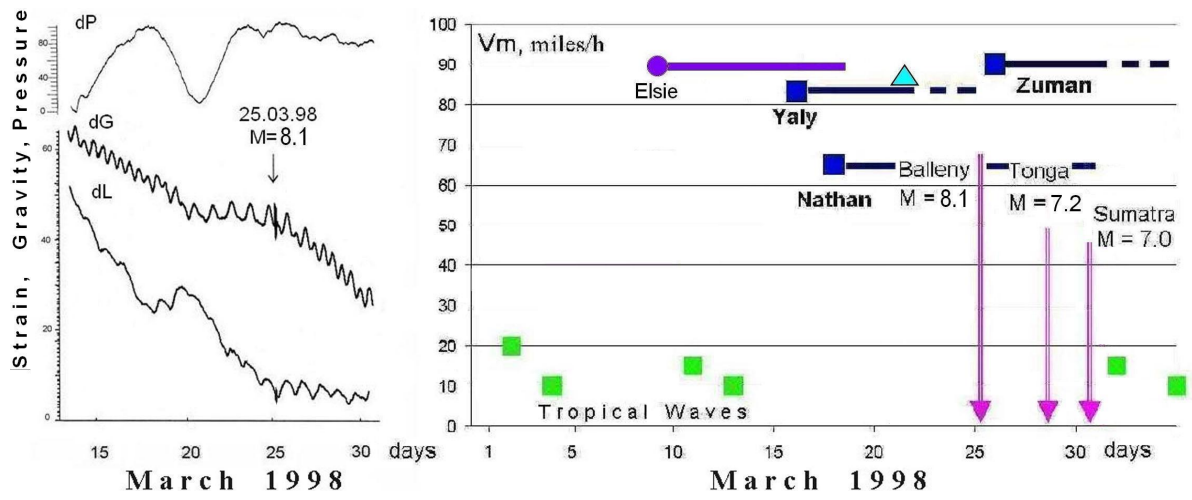

Fig. 3. Comparison of strain (dL), gravity $(d G)$, and baric $(d P)$ perturbations, detected in Moscow region (left), with the seismic (vertical arrows) and cyclone (horizontal lines) activities in South Pacific and Indian Oceans (right).

\section{NHESSD}

2, 935-961, 2014

\section{Earthquake and hurricane coupling}

M. N. Dubrov et al.

\section{Title Page}

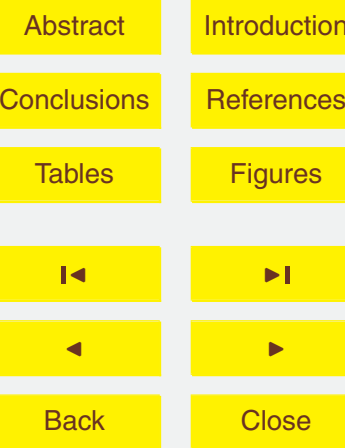

Full Screen / Esc

Printer-friendly Version

Interactive Discussion 


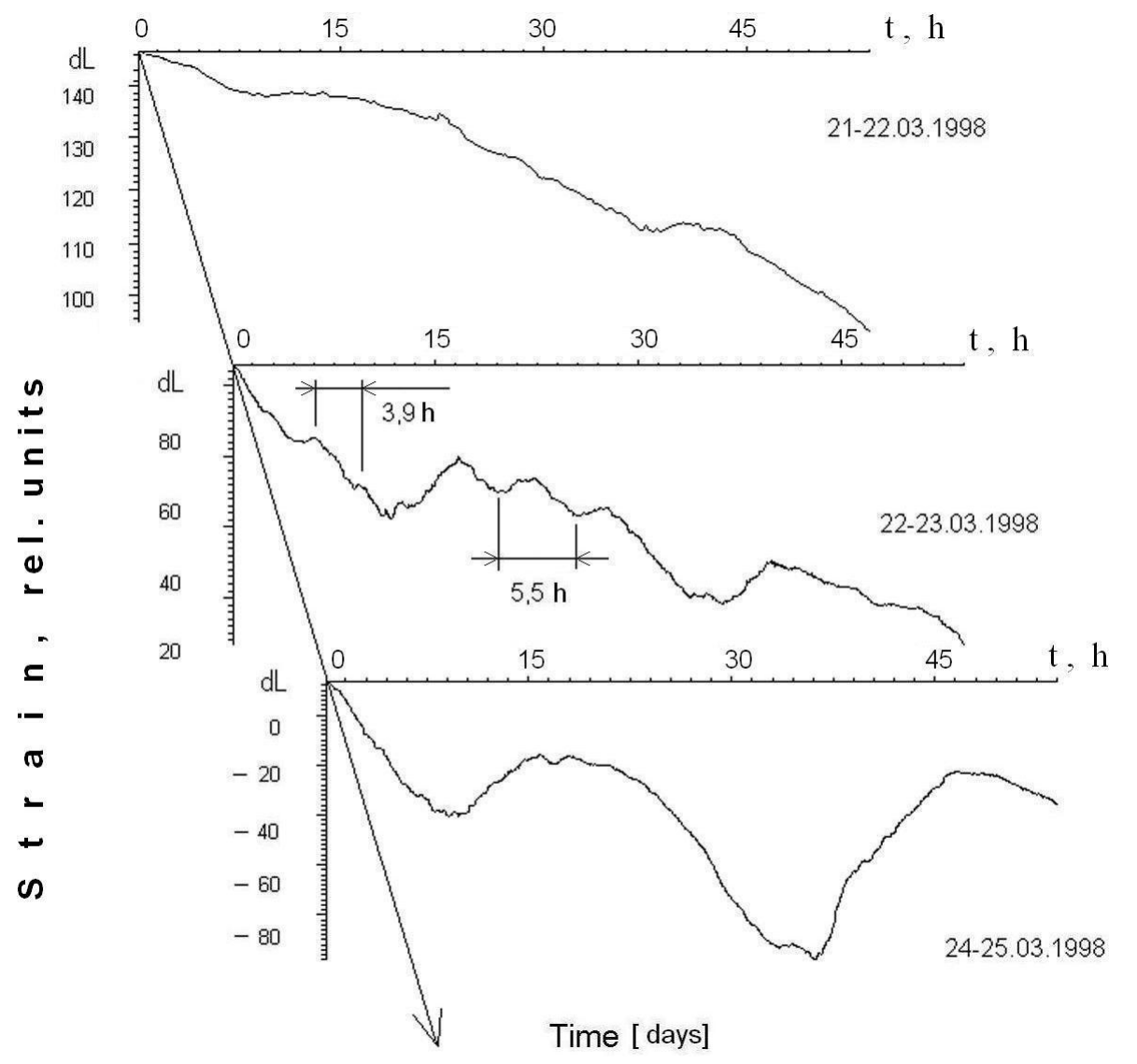

Fig. 4. Ultra-long period strain-baric oscillations detected by laser interferometer in Moscow region 22-23 March 1998 before the strongest earthquake of 1997-1998 seasons (duration of every track recordings are $48 \mathrm{~h}$ ).

\section{NHESSD}

2, 935-961, 2014

Earthquake and hurricane coupling

M. N. Dubrov et al.

Title Page

\begin{tabular}{c|c|}
\hline Abstract & Introduction \\
\hline Conclusions & References \\
\hline Tables & Figures \\
\hline $\mathbf{1}$ & \multicolumn{1}{|c|}{} \\
\hline 4 & - \\
\hline Back & Close \\
\hline Full Screen / Esc
\end{tabular}

Printer-friendly Version

Interactive Discussion 

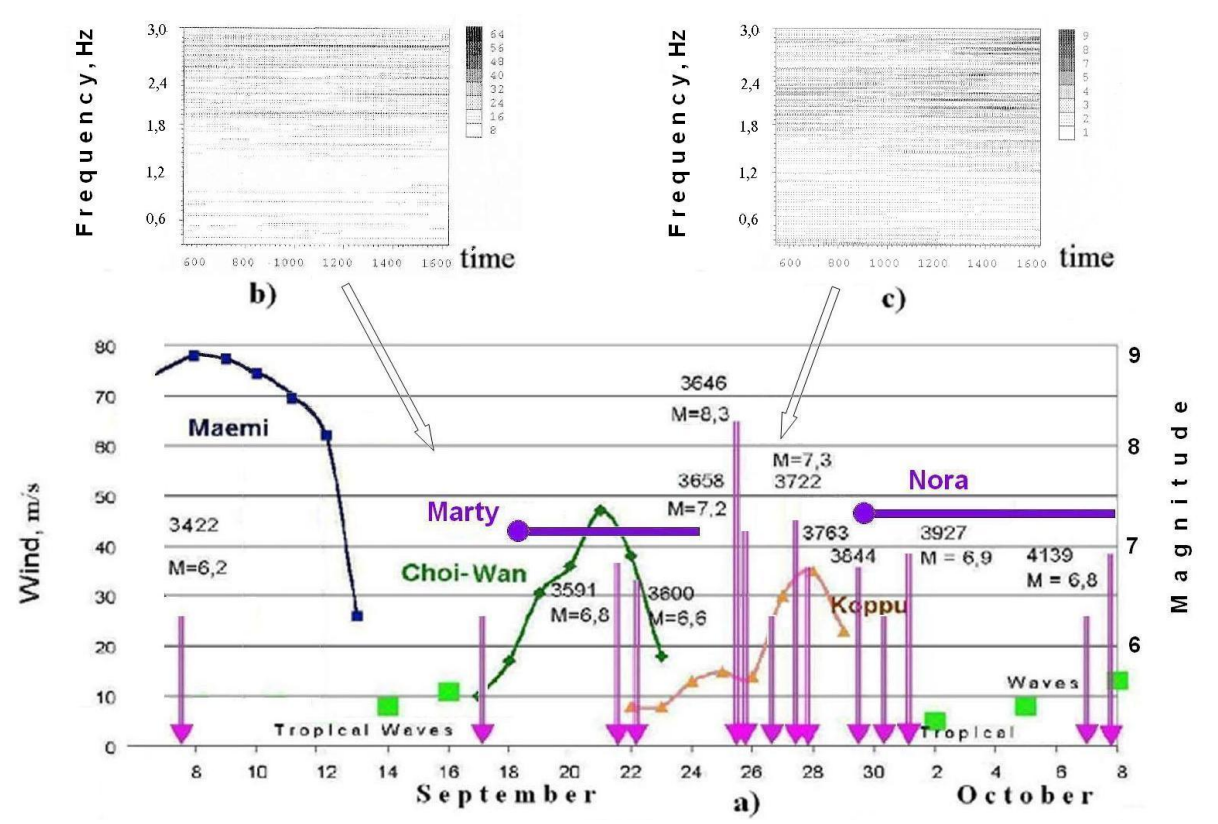

Fig. 5. Comparison of seismic-cyclone activities in North Pacific Ocean in SeptemberOctober 2003 (a) and micro-seismic oscillations in Moscow region: background (b) and calm (c) before the Central Russia (Altai) earthquakes.

\section{NHESSD}

2, 935-961, 2014

\section{Earthquake and hurricane coupling}

M. N. Dubrov et al.

\section{Title Page}

\begin{tabular}{|c|c|}
\hline Abstract & Introduction \\
\hline Conclusions & References \\
\hline Tables & Figures \\
\hline $\mathbf{1}$ & \\
\hline & \\
\hline Back & Close \\
\hline Full Screen / Esc \\
\hline
\end{tabular}

Printer-friendly Version

Interactive Discussion 


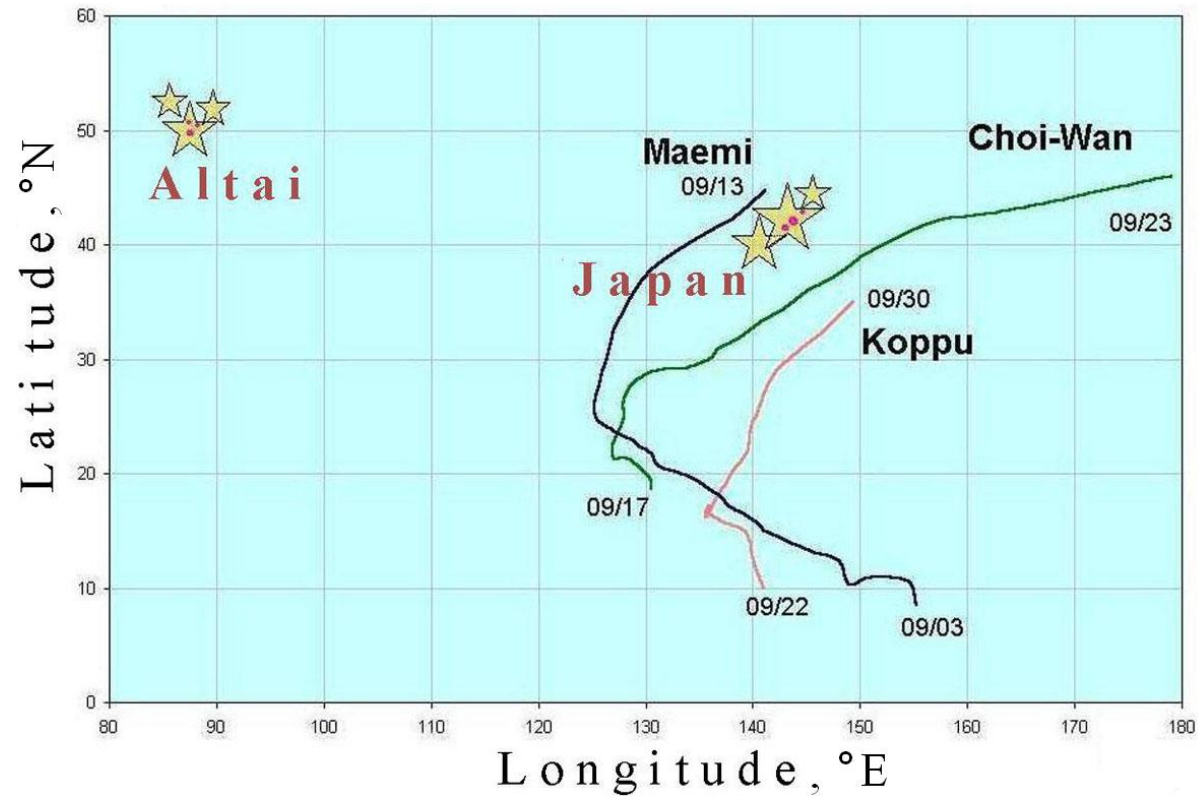

Fig. 6. The Japanese and Altai earthquake centers (denoted by stars) and typhoon traces in North West Pacific Ocean in September 2003.

\section{NHESSD}

2, 935-961, 2014

\section{Earthquake and hurricane coupling}

M. N. Dubrov et al.

\section{Title Page}

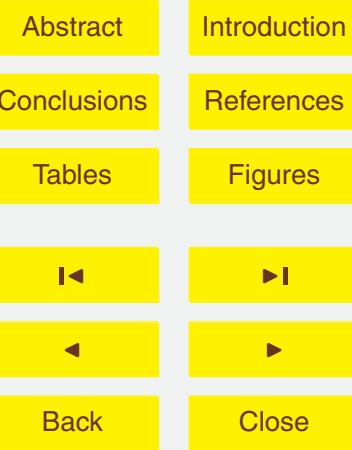

Full Screen / Esc

Printer-friendly Version

Interactive Discussion 


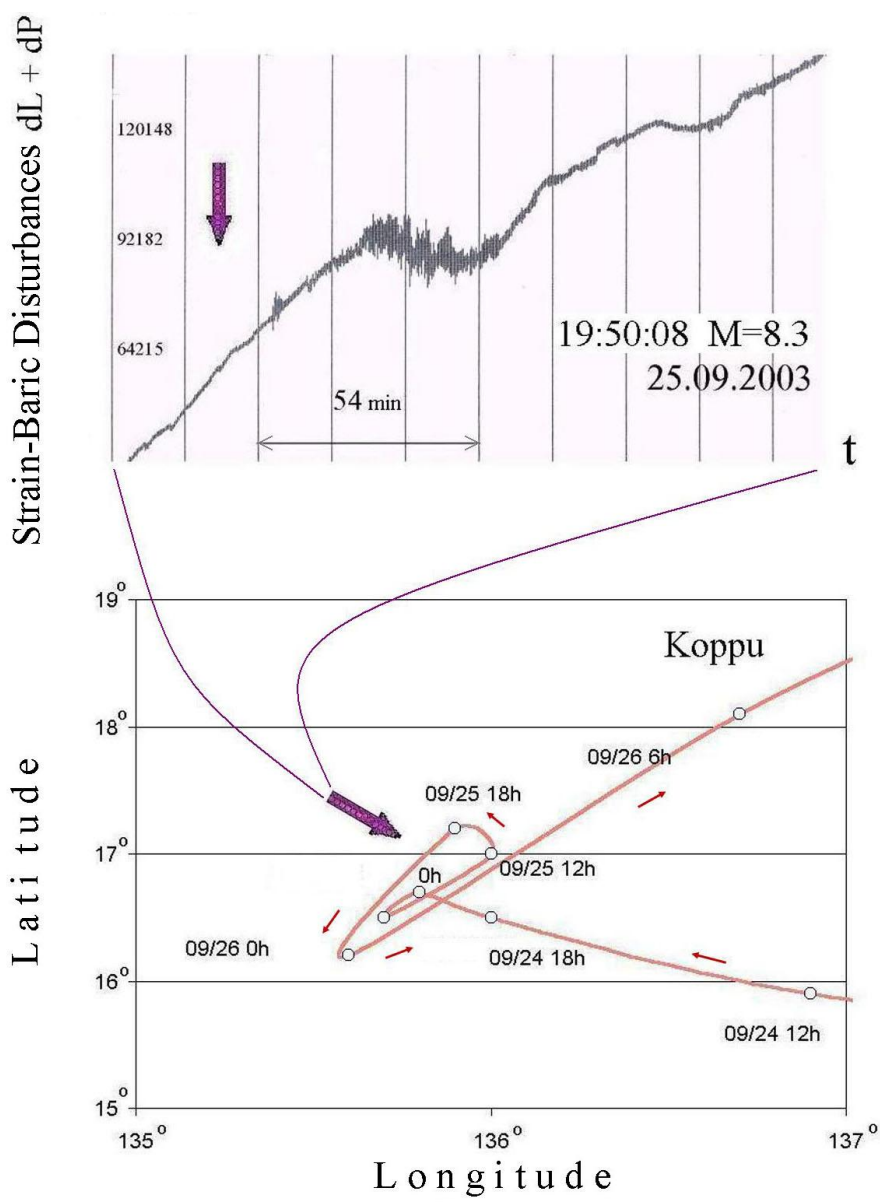

\section{NHESSD}

2, 935-961, 2014

\section{Earthquake and hurricane coupling}

M. N. Dubrov et al.

\section{Title Page}

\begin{tabular}{c|c} 
Abstract & Introduction \\
\hline Conclusions & References \\
\hline Tables & Figures \\
\hline
\end{tabular}

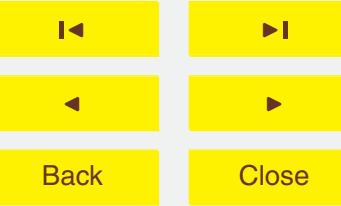

Full Screen / Esc

Printer-friendly Version

Interactive Discussion 